\title{
Reseña bibliográfica: Thomas, R. (2019). Polis Histories, Collective Memories and the Greek World, Cambridge: Cambridge University Press, xii +490 pp.
}

Palabras claves: Historiografía local - Grecia helenística - Comunidades locales

Keywords: Local historiography - Hellenistic Greece - Local communities

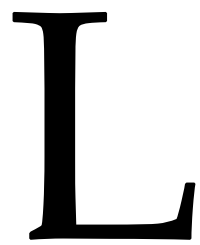

as viejas certezas de la filología clásica sobre la decadencia de la historiografía helenística se han desdibujado no hace mucho tiempo. ${ }^{1}$ Esta actitud negativa estaba basada en diversos prejuicios, en particular, en la convicción de que estas historias eran el producto de un estéril interés anticuario frente al pasado, de alcance estrictamente local y que, además, carecía por completo de la agudeza intelectual y el sentido político de la gran historiografía griega del siglo $\mathrm{V}$ a.C. Ese era el diagnóstico general. Con algunas excepciones notables, particularmente la de Polibio en el siglo II a.C., se pensaba que los escritos perdidos, bien perdidos estaban. El "Campo de ruinas" (Trümmerfeld) de la historiografía griega entre los siglos IV-II a.C. (Strasburger, 1977, pp. 14-15), del que podía rescatarse apenas un 2,5\% del total de las historias escritas en aquellos siglos, en fragmentos y testimonios, fue metódicamente reconstruido por Felix Jacoby durante la primera mitad del siglo XX. Estos testimonios y fragmentos han comenzado a ser explorados en las últimas décadas con nuevos ojos.

Por un lado, se ha refinado mucho la metodología de trabajo historiográfico con dichos fragmentos. La sutileza de los nuevos abordajes textuales ha revelado el filtro inherentemente distorsivo interpuesto por los autores tardíos que hicieron uso y "citaron" esa historiografía hoy perdida. Algunos de ellos mutilaron los pasajes debido a que su interés individual residía en recopilar únicamente hechos curiosos o anécdotas del pasado, tal como ocurría con escritores como Ateneo y Plutarco, que explotaron intensivamente estas obras como cantera para anécdotas o ejemplos morales. Otros autores, por el contrario, con una actitud más enfocada en la función polémica de la cita a sus antecesores, como es el caso de Polibio en su famoso libro XII, actuaron como "textos de cubierta" (cover-texts). Su diafragma solo dejaba ver del autor citado lo que

\footnotetext{
${ }^{1}$ Basadas a su vez en actitudes antiguas, como el aticismo dominante en la literatura en griego de época imperial romana, el mayor interés por aquellos tiempos por la época griega clásica, así como la moda de los resúmenes de obras antiguas para el público imperial: Baron (2013, p. 5).
} 
estrictamente servía a los fines de minar los argumentos del mismo y poder emerger, así, como una autoridad en la exploración del pasado frente a los predecesores. ${ }^{2}$ Este tipo de procedimientos de cita antigua nos ha privado, en efecto, de los contextos narrativos originales de los fragmentos. Aunque cuidadosamente compilados y clasificados genéricamente en Die Fragmente der griechischen Historiker ("Los Fragmentos de los Historiadores Griegos”) de Jacoby, o ahora en su traducción y comentario al inglés por diversos autores para el Brill's New Jacoby, a veces estos fragmentos así editados con criterios modernos contribuyen a perpetuar una lectura sesgada ya ofrecida por los cover-texts. Estos "textos de cubierta" han transformado el sentido original de la información en dos etapas. En el mundo antiguo, por los procedimientos mencionados de inclusión de las palabras de un autor hoy perdido en la obra de otro autor. En el mundo moderno, por la creación artificial de un no-contexto narrativo completamente nuevo, que por la inserción aislada de fragmentos quirúrgicamente delimitados por Jacoby en su edición, ha desviado el foco del contexto original y del del texto de cubierta.

Por otro lado, la evaluación histórica moderna del mundo de las ciudades entre los siglos IV y II a.C. también ha variado en los últimos 25 años. Una nueva consideración sobre la posición y el papel de las póleis en el período helenístico, más atenta y sensible a la vitalidad de su experiencia histórica, aunque siempre fuertemente condicionada por la existencia de los grandes imperios herederos de Alejandro, ha permitido repensar la orientación política presente de múltiples historias escritas en el mundo griego por aquella época. En tal sentido, la imagen de un mundo de intelectuales griegos, de espalda a una realidad presente angustiante, situados en una torre de marfil, y tratando de refugiarse en una investigación anticuaria sobre el pasado y las tradiciones, sin preocuparse por la política contemporánea (como sí lo habían hecho Heródoto, Tucídides o Jenofonte), resulta impensable en la actualidad. Estos dos cambios generales en la historiografía son, entonces, importantes para dimensionar el aporte realizado por el libro que estamos reseñando.

Rosalind Thomas, una historiadora que no necesita presentación, enmarca su nuevo libro en estas dos líneas renovadoras. Por un lado, realiza una contribución a los estudios de historiografía helenística, al proponer una relectura de las historias locales escritas en el espacio egeo (Grecia, las islas y Asia Menor), entre la segunda mitad del siglo IV y el II a.C. Por otro lado, enmarca su discusión en el universo de la polis postclásica, al reflexionar sobre la relación entre este tipo de historias locales y la experiencia política y cultural contemporánea de las póleis, islas y confederaciones. Al respecto, un énfasis particular está puesto en reconocer, primero, el lugar al que cada pólis aspiraba, como comunidad con una historia propia, en el marco de un "nuevo helenismo" caracterizado por una marcada conectividad cultural mediterránea y próximo oriental, entre múltiples

\footnotetext{
2 Sobre las implicancias metodológicas de los "textos de cubierta" (cover-texts), que "preservan", "esconden" y "encierran" al texto precursor: Bollansée (2005, p. x). Sobre la polémica con los antecesores, sigue siendo central el libro clásico de John Marincola (2004, pp. 225-236), quien ha provisto ahora una utilísima selección de textos de la historiografía griega antigua: Marincola (2017).
} 
comunidades que reconocían en la cultura griega un lenguaje eficiente para la comunicación. Segundo, junto con la tendencia anterior, pero en abierta oposición, la actitud frente a la dimensión competitiva y agonal, que perseguía la definición de la propia existencia en un mundo violento y generalmente inestable.

En ese sentido, Thomas estructura los contenidos del libro en diez capítulos, que en orden y traducidos al español son los siguientes: 1) “¿Qué son las historias de póleis? Historia popular y sus audiencias" (pp. 29-73); 2) "Cuentos para contar: tò $\mu v \theta \tilde{\omega} \delta \varepsilon \varsigma$ " (pp. 74-99); 3) “¿Etnografía para los griegos? La polis como un nuevo tema para la historiografía" (pp. 100-150); 4) "Forjar la comunidad: historiografía acumulativa” (pp. 151-176); 5) “Orígenes, fundaciones y etnicidad: griegos y no griegos" (pp. 177-226); 6) “Salvar a la ciudad: ¿Historia política o Parádoxa? Mileto y Lesbos (pp. 227-274); 7) “Polis en cambio: dislocación y privación de derechos en Samos" (pp. 275-315); 8) "Historias atenienses de la polis" (pp. 316-357); 9) "Las politeíai aristotélicas y las historias locales" (pp. 358-385); 10) “Historias de póleis e islas y el mundo clásico tardío y helenístico: ¿un nuevo helenismo? (pp. 386-409). Se incluyen también tres apéndices: uno sobre la ciudad de Mileto (pp. 410-414); otro con un breve listado de los historiadores de póleis, islas y éthnos del siglo IV a.C. (pp. 415-416) y, finalmente, un tercer apéndice en el que se proporciona un listado sistemático de los historiadores locales que aparecen en Jacoby, atendiendo a criterios diferentes para la "clasificación" a los generalmente tenidos en cuenta por el filólogo alemán (pp. 417-445). Siguen una bibliografía completa y exhaustiva (pp. 446-474), un útil índice de lugares (pp. 475-479) y uno con los nombres mencionados en el libro (pp. 480-490).

La tabla de contenidos revela una aspiración al conocimiento general, incluso exhaustivo, sobre la práctica de la historiografía local, pero con un foco en casos específicos situados dentro del área egea del mundo griego (Atenas, Mégara, las islas y la costa de Asia menor). Esto implica lógicamente recortes importantes, que dejan afuera, por ejemplo, a la importante historiografía siciliana o a la del Mar Negro, particularmente la producida en Heraclea Póntica, aun cuando se incorpore alguna vez información, por ejemplo, sobre Locros Epicefirios en el sur de Italia. Como hemos señalado, el marco temporal se restringe a los siglos IV-II a.C., dejando de lado las producciones bajo dominio romano, a fin de entender el juego y la dinámica existente entre historia local y una época particular del Mediterráneo oriental. En líneas generales, el recorte tanto temporal como geográfico es convincente y permite explorar en profundidad algunos casos bastante significativos.

Aun cuando el tema de la historiografía local haya sido frecuentemente visitado en las últimas dos décadas (Schepens, 2001; Ambaglio, 1998; 2001; Tober, 2017), este es el primer estudio monográfico sistemático publicado y las ideas que en él se desarrollan tienen cierta importancia para la comprensión del problema. En particular, su clave histórica de integración de historiografía local y situación política específica en cada pólis, sin perder de vista el cuadro general global del "nuevo helenismo", permite abandonar, en mi opinión, definitivamente dos de los presupuestos genéricos más 
fuertes de la empresa intelectual de Jacoby. En principio, la idea de que la historiografía local, o la escritura de hóroi, había surgido específicamente como una respuesta políada a la gran historia de Heródoto, quien había omitido en su relato la participación de algunas póleis y a otras las había pintado de forma bastante negativa. Pero la autora también añade elementos para sepultar la hipótesis de que las historias de Atenas (Atthídes), escritas por los atidógrafos entre los siglos IV-III a.C., y las historias locales helenísticas por extensión, respondían principalmente a las necesidades de promoción y agonales de diversas familias aristocráticas. La historia habría sido, según esta lectura de Jacoby, un terreno disputado en el que había que asegurarse un lugar privilegiado en las memorias colectivas de las respectivas comunidades (en el pasado mítico, heroico e histórico) (Jacoby, 1949; cf. Harding, 2007).

De cara a estas cuestiones, Thomas muestra, particularmente en los capítulos 4, 5, 6, 7 y 8, que la proliferación de escrituras históricas de base local tenía causas más profundas (y menos "individuales"). El objetivo de forjar una idea de comunidad, de crear una historia compartida para la totalidad de los habitantes de una polis (como revela la idea de una "historiografía acumulativa" típica de la época), coincide generalmente con momentos de necesidad de afirmación frente a diversas situaciones. Estas historias locales no parecen haber respondido a aspiraciones de distinción meramente aristocráticas. Por ejemplo, la afirmación frente a vecinos poderosos (i.e. Mégara), superar eventos recientes de dislocación política de una pólis (i.e. Colofón), afirmar el control sobre el territorio y relacionarse diplomáticamente (i.e. Mileto o Eritras), elidir la memoria de un traumático conflicto cívico reciente (stásis), que había privado de derechos políticos a buena parte de la ciudadanía (i.e. Samos), o bien experimentar de la mejor manera un presente de subordinación política (i.e. Atenas). A partir de ejemplos notables, la autora muestra cómo distintos historiadores locales se involucraron con un proceso activo común de (re)imaginación de la comunidad política en contextos políticos fluidos y cambiantes, amenazantes y desafiantes. Sus acciones individuales, en tal sentido, no parecen ser solo parte de una respuesta intelectual, erudita, sino, sobre todo, de una acción política y cultural enfocada en el horizonte de sus propias póleis, vistos desde adentro, como un todo indiviso (como una "comunidad política", p. 1), capaz de proyectarse al resto del mundo griego de esa manera.

En los primeros capítulos, es decir 1, 2 y 3, por su parte, se discute el carácter general de estas historias locales. Esto es bastante complejo, dado que las mismas constituyen la práctica historiográfica más extendida durante esos siglos. En efecto, Thomas cuenta un total de unas 530 obras atestiguadas en la época (pp. 10, 30 y “Apéndice 3", pp. 417-445). ${ }^{3}$ En ese sentido, se explora allí una serie de cuestiones importantes, en las que, sin llegar a proponer una generalización sobre la práctica de la historia local, permiten comprender un abordaje político-cultural común de estas historias en el resto del libro. Así, la autora llama la atención sobre algunos de los rasgos conocidos del género de la

\footnotetext{
${ }^{3}$ Como señaló Guido Schepens, Tucídides y Polibio son la excepción, no la norma en la historiografía.
} 
historia local: En estas historias se advierte un patriotismo marcado (Lokalpatriotismus); un interés por las costumbres y los cultos políadas, con foco en el origen remoto de la comunidad y en el presente, que deja una gran nebulosa en el medio, según el extendido "efecto reloj de arena" (hourglass effect) -típico de las tradiciones orales etnográficamente estudiadas-. También advierte la autora un paralelo del auge de este tipo de historias con el fenómeno de incremento en la información histórica incluida en inscripciones cívicas locales del período, así como con la creciente valoración del pasado de la polis y su uso cultural activo en la diplomacia. Asimismo, se nota la integración en los relatos históricos de información proveniente de cuentos populares $\mathrm{y}$, finalmente, su vinculación con la topografía y la memoria local de la ciudad. Esto lleva a la autora a discutir las nociones de etnografía, anticuarismo y historíe en el sentido herodoteo del término ("que abarcaba la indagación sobre el pasado y el presente, costumbres, creencias religiosas, peculiaridades geográficas y maravillas o tháumata", p. 150). Su conclusión al respecto es que tenemos que entender estas historias locales como formas especiales de historíe, de historia como indagación en el sentido herodoteo, pero con un cambio fundamental en lo que se consideraba digno de recordar. En efecto, estas historias constituyen el signo visible de un descentramiento de la actitud etnográfica griega hacia el mundo externo, el de los bárbaros "otros", y una progresiva concentración sobre los sentidos y experiencias de la propia comunidad, con el acento puesto en el pasado, en los hábitos y en el lugar, pero en tanto los mismos influyen aún de algún modo en el presente y contribuyen a pensar y constituir la comunidad y la identidad local.

Si de Atenas a Mileto, pasando por Mégara, Delos, Paros, Eritras y los demás casos abordados en el libro se observa un fenómeno diverso, pero a la vez unitario, de autoexamen y autoafirmación del fenómeno políada en la historiografía local, en la segunda mitad del siglo IV a.C. también se asistió a un examen de las tradiciones locales y sus historias desde una perspectiva externa cuando se popularizó el género de las politeíai aristotélicas. A ese tema está dedicado el capítulo 9. Se advierte que esta etiqueta "constitucional" remite a algo más complejo, más completo, que una recolección fáctica de "constituciones" de diversos Estados, y que las mismas deben ser entendidas como parte de un género literario propio de los siglos V-IV. El mismo comenzaría con un interés por Esparta o Creta y habría supuesto la necesidad de un abordaje completo de: "la naturaleza de la sociedad, sus costumbres y hábitos, sus orígenes e historia pasada, así como también sus estructuras políticas, magistraturas y moneda" (p. 377). De las 158 politeíai escritas por Aristóteles y su escuela solo se ha conservado completa, de manera fortuita, la de Atenas, devuelta por las arenas del desierto a fines del siglo XIX. Thomas muestra de manera clara, sin embargo, cómo los fragmentos conservados revelan trazas de un proyecto de creación de visiones estilizadas de cada una de las comunidades definidas como objeto de estudio por parte del Peripato: "la redacción de politeíai efectivamente capturaba y cristalizaba una imagen y relato coherentes de una polis y su politeía... creaban visiones cristalizadas de la comunidad" (p. 385). 
En ese sentido, se advierte una convergencia entre los relatos de los historiadores locales y la obra de la escuela aristotélica, en tanto ambos, unos desde adentro y la otra desde afuera, reconocían, en concordancia con el clima de época, que la polis era un objeto de estudio histórico axiólogos, es decir, "digno de estudio". Este solapamiento de formas de aproximación e intereses temáticos es recurrente. Un ejemplo particularmente notable es el testimonio de Polibio (XII.5-11), que, escribiendo en el siglo II a.C., da cuenta de las tradiciones de los locrios epicefirios sobre la fundación de su propia ciudad y, significativamente, alinea el relato de la comunidad con el discurso de Aristóteles sobre este "relato de fundación" (ktísis) para oponer ambos a la indagación histórica de Timeo de Tauromenio, que en el siglo III a.C. había desconfiado de la historicidad de lo que Aristóteles había escrito el siglo anterior.

Rosalind Thomas ha escrito, por lo tanto, un libro importante. Su objeto de estudio es verdaderamente complejo, basado en un corpus documental desafiante, cuya interpretación y puesta en perspectiva histórica ha implicado un gran trabajo de exégesis y contextualización histórica. El enfoque teórico desde el cual se ha pensado el problema, el de las tradiciones orales, la memoria local y las comunidades imaginadas, se ha mostrado muy útil. Obviamente, algunas de las afirmaciones de la autora pueden ser objeto de discusión, así como también algunas de sus interpretaciones puntuales, pero las objeciones tienen que ver más con la posibilidad de pensar matices para algunas de las ideas expuestas a lo largo de la obra, que con impugnar la tesis general.

En primer lugar, me parece un poco infructuoso el esfuerzo dedicado a identificar el "género" de estas historias, a tratar de discutir si estamos ante un tipo de etnografía o, en cambio, si podemos considerarlo una historíe en la más verdadera tradición reflexiva jonia. Creo que los estudios sobre el género historiográfico han mostrado, a partir de los importantes señalamientos al respecto de John Marincola (1999), que las estrategias narrativas y las formas de abordar el pasado siempre se constituyen sobre la base de discursos híbridos, en los que las elecciones genéricas concretas responden a un complejo juego entre tradición e innovación. Establecer fronteras genéricas demasiado rígidas conspira, en ese sentido, en contra de entender estas prácticas como formas de "historiografía" antigua.

Por supuesto, la historiografía en el mundo griego no fue solo una exploración erudita del pasado, ni tampoco una mera legitimación pragmática del presente, sino que implicó en buena medida una posible proyección hacia el futuro. ${ }^{4}$ El problema es que estas historias locales no han sobrevivido, sus tramas narrativas originales están rotas, y, además, los autores posteriores que recogieron información de ellas y nos transmitieron sus "fragmentos" se detuvieron principalmente en datos curiosos del pasado remoto.

\footnotetext{
${ }^{4}$ Particularmente interesante es la perspectiva reciente de Jonas Grethlein (2013), que pone el acento en el télos de las historias antiguas narradas desde la perspectiva presente de un historiador, que, como sujeto situado en el presente, pero orientado al futuro, frecuentemente mina el télos presente y proyecta la experiencia narrada hacia el horizonte de espera, potenciando la didáctica del discurso histórico antiguo y su pretendida utilidad predictiva.
} 
Esto ha dado pie, como hemos advertido ya, a entender a estos historiadores locales simplemente como "anticuarios" o "eruditos" desinteresados por el presente. Thomas demuele de forma sistemática esta visión sesgada y muestra, por el contrario, que el presente era importante para estos autores, más aún, que era una arena central para pensar la conformación y la unidad de sus respectivas comunidades cívicas helenísticas. De cualquier manera, los fragmentos existentes no alcanzan para reconocer en acción las operaciones narrativas historiográficas concretas, en las que cada uno de estos historiadores puso en juego, o no, la relación entre pasado-presente y futuro (o proyección de su indagación), lo que permitiría completar el sentido de una obra histórica en el mundo griego, entendida stricto sensu como historíe. Lo que propone Thomas, en tal sentido, no deja de ser estimulante, pero es apenas indiciario.

En segundo lugar, si bien es importante la crítica a Jacoby y su idea de que estas historias locales respondían principalmente a las necesidades competitivas de las élites aristocráticas tardoclásicas y helenísticas, que pugnaban por apropiarse del pasado y mejorar así la imagen personal y familiar en el mismo, una acentuación excesiva del carácter comunitario de estas empresas historiográficas debería dejar espacio para algunos matices. Como en el famoso eslogan del Partido en 1984 de George Orwell, que manifestaba la necesidad de dominar el presente como un medio para controlar el pasado y así poder controlar el futuro, las elites políadas, según Jacoby, habían recurrido a la historia pasada para defender su posición en el presente y asegurar el porvenir de sus respectivas familias. La interpretación crítica de Thomas, insisto, es un buen correctivo a esta visión elitista extrema del poder, aunque, me parece, que deja muy poco lugar para las excepciones. Y quizá la historia de la polis helenística no tenga que ser disociada dramáticamente de la realidad de un equilibrio competitivo entre comunidad y élite.

En efecto, se advierte una convergencia con lo ocurrido a nivel monumental, epigráfico y hasta estatuario en las póleis desde el siglo IV a.C. A partir de los excelentes estudios de John Ma (2012; 2013) sobre honores públicos, estatuas y las póleis helenísticas, estos discursos históricos locales podrían ser interpretados como un resultado de esfuerzos comunitarios por construir una historia local sin fisuras. La vitalidad de la polis entre los siglos IV y II a.C., la negociación efectiva con las élites y la canalización de sus recursos en beneficio común parece ser una constante de la dinámica política de la época. Sin embargo, comunidad y élite negociaron, y disputaron poder, prestigio y visibilidad en el espacio público de las póleis, y, aunque moderadas, las élites siguieron buscando un rol protagónico y visible, lo que fue reconocido y controlado oficialmente por medio de decretos honoríficos del dêmos, que buscó capitalizar este interés individual.

¿En verdad las élites se desdibujaron en estas historias locales helenísticas? Hay algunos indicios de negociación, que parecen indicar que las comunidades habilitaron ciertos espacios a algunas ambiciones de preeminencia y distinción de las élites sin hacerlas, con todo, determinantes en la historia local. Por ejemplo, en la mencionada 
historia local de Locros Epicefirios. Aunque Polibio recupera allí la politeía locria de Aristóteles, es claro que el relato aristotélico había tenido su origen, a su vez, en una historia local, que coincidía además con la opinión actual de los testigos polibianos. En ese relato de fundación, visiblemente conectado con el presente de Locros, salta a la vista el papel central de los miembros de la aristocracia local de las llamadas Cien Casas. En efecto, el motivo de la polémica historiográfica planteada por Polibio es el intento por parte de Timeo de negar que estas familias descendieran de las doncellas locrias emparejadas con esclavos en la Locros de Grecia durante la Guerra Mesénica antes de la fundación de la Locros itálica. Sin embargo, como se desprende del texto de Polibio, del testimonio de los propios locrios y de la cita a Aristóteles esto podía tener una importancia central para legitimar, desde el origen de la ktísis, de la fundación en el pasado remoto, la posición especial de una fracción de la élite cívica todavía en pleno siglo II a.C.

También en la obra del propio Polibio, se ha indicado alguna vez que su relato del libro II sobre la historia primitiva de los aqueos, y sobre el desarrollo de la Confederación aquea desde sus primeros años hasta la época en la que estaba escribiendo el historiador megalopolitano, habría sido concebido originalmente como un relato independiente de corte local, como una Achaiká ("un relato sobre los aqueos", "unas cosas de los aqueos") (Pol. II.37-70). ${ }^{5}$ Podríamos incluso considerar este relato interno como una "historia local" incrustada en la "historia universal" del autor. Allí, por supuesto, Polibio pone el acento fundamentalmente en los logros colectivos de los aqueos. Así, se inventa una comunidad original, coherente y unificada, que es incluso más antigua y más prestigiosa de lo que la arqueología u otros testimonios podrían llegar a permitir corroborar actualmente. Se trata de una comunidad reconocida por los demás griegos, los continentales y los de la Magna Grecia, debido a sus virtudes morales y su buen ordenamiento político, y que, en última instancia, transita su historia primigenia desde el pasado heroico hasta la época helenística exhibiendo una sorprendente (e irreal) continuidad y estabilidad institucional democrática. Sin embargo, pese a esta imagen de "unidad", también se rescata el aporte concreto en el logro de la misma de determinados individuos, responsables del auge "actual" en la primera mitad del siglo II a.C.: las acciones de hombres como Arato, Filopemén, Licortas y, por supuesto, el propio Polibio son realzadas de forma prominente. Desde luego, el carácter fragmentario, el énfasis en las descripciones pasadas y en las costumbres a la hora de citar, no nos permiten acceder a nada parecido entre los cientos de historiadores fragmentarios locales a este relato conservado intacto, pero los indicios me parece que piden por una matización de la idea de unidad absoluta políada en los relatos de aquella época.

Estas reservas, con todo, son estrictamente cuestiones puntuales y pueden bien ser objeto de un nuevo debate, pero de ningún modo pueden opacar la importancia del

\footnotetext{
${ }^{5}$ Para la idea de la Achaiká como un relato compuesto de forma autónoma luego fundido en las Historias: Laqueur (1913, pp. 10-11) y Gelzer (1964, pp. 123-154).
} 
presente estudio de Rosalind Thomas. Polis Histories, Collective Memories and the Greek World es un ambicioso estudio, que recorre los sinuosos senderos de la tradición fragmentaria de historiadores locales tardoclásicos y helenísticos ("el campo de ruinas" como tan maravillosamente lo denominó Hermann Strasburger), y, solo por el hecho de haber propuesto una lectura general de este complejo y enorme palimpsesto que constituye la historiografía helenística, Thomas ya ha realizado un aporte más que significativo. Sin embargo, el alcance del estudio no se limita a eso. También la propuesta de establecer un vínculo entre ese cúmulo de historiografía epicórica y el momento histórico en el que se volvieron más frecuentes este tipo de obras merece una mención especial. En ese sentido, Polis Histories propone también un recorrido vivaz por algunas de las apuestas políticas y culturales de la polis entre los siglos IV y II a.C., al tiempo que inserta esas apuestas en un contexto geográfico y cultural más amplio para dar cabida al "nuevo helenismo" imaginado tras Alejandro Magno. En el mismo, las póleis interactuaron y se relacionaron de forma cada vez más intensa, dentro de una escala espacial nunca antes vislumbrada. La estimulante interpretación de la autora de algunas parcelas del "campo de ruinas" historiográfico helenístico permite, entonces, reconocer cómo se pensaron a sí mismas esas comunidades políadas e isleñas helenísticas, hacia el interior, pero también cómo ese autoexamen y autorrepresentación ocurrió como resultado de una integración mayor o menor dentro de la red más amplia del helenismo tardío: "Fue la celebración de diferencias dentro de la cultura compartida" (p. 397). En el fondo, estamos ante la historia de un vasto y aún poco explorado fenómeno que unió culturalmente a la cuenca del Mediterráneo en un contexto de profunda fragmentación política tras la muerte de Alejandro Magno.

\section{Referencias bibliográficas}

Ambaglio, D. (1998). Per il reperimento di materiali di storia locale greca: Diodoro,

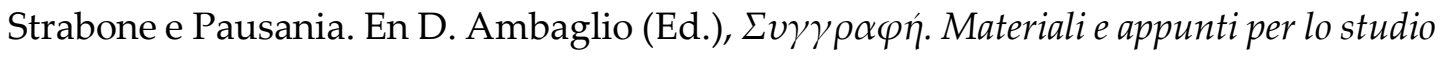
della storia e della letteratura antica (pp. 93-109). Como: New Press.

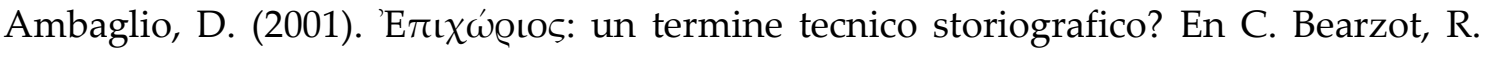
Vattuone y D. Ambaglio (Eds.), Storiografia locale e storiografia universale (pp. 93-109). Como: New Press.

Baron, Ch. (2013). Timaeus of Tauromenium and Hellenistic Historiography. Cambridge: Cambridge University Press.

Bollansée, J. (2005). Preface. En G. Schepens y J. Bollansée (Eds.), The Shadow of Polybius. Intertextuality as a Research Tool in Greek Historiography (pp. ix-xi). Leuven: Peeters.

Gelzer, M. (1964). Kleine Schriften, vol. III. Wiesbaden: Franz Steiner.

Grethlein, J. (2013). Experience and Teleology in Ancient Historiography. "Futures Past" from Herodotus to Augustine. Cambridge: Cambridge University Press. 
Harding, P. (2007). Local history and Attidography. En J. Marincola (Ed.), A Companion to Greek and Roman Historiography (pp. 180-188). Oxford: Blackwell.

Jacoby, F. (1949). Atthis. The Local Chronicles of Ancient Athens. Oxford: Clarendon Press. Laqueur, R. (1913). Polybius. Leipzig: Teubner.

Ma, J. (2012). Honorific Statues and Hellenistic History. En Ch. Smith y L. M. Yarrow (Eds.), Imperialism, Cultural Politics, \& Polybius (pp. 230-251). Oxford: Oxford University Press.

Ma, J. (2013). Statues and Cities. Honorific Portraits and Civic Identity in the Hellenistic World. Oxford: Oxford University Press.

Marincola, J. (1999). Genre. Convention and innovation in Greco-Roman historiography. En Ch. Kraus (Ed.), The Limits of Historiography: Genre and Narrative in Ancient Historical Texts (pp. 281-324). Leiden-New York: Brill.

Marincola, J. (2004). Authority and Tradition in Ancient Historiography. Cambridge: Cambridge University Press.

Marincola, J. (2017). On Writing History from Herodotus to Herodian. Penguin Random House: London.

Schepens, G. (2001). Ancient Greek City Histories: Self-definition through History Writing. En K. Demoen (Ed.), The Greek City from Antiquity to the Present (pp. 3-25). Leuven: Peeters.

Strasburger, H. (1977). Umblick im Trümmerfeld der griechischen Geschichtsschreibung. En Historiographia antiqua. Commentationes Lovanienses in honorem W. Peremans septuagenarii editae (pp. 3-52). Leuven: Leuven University Press.

Tober, D. (2017). Greek local historiography and its audiences. CQ, 67 (2), 460-484.

\author{
Álvaro M. Moreno Leoni \\ Universidad Nacional de Río Cuarto/ \\ Universidad Nacional de Córdoba-CONICET \\ moreno.leoni@gmail.com
}

Para citar esta reseña:

Moreno Leoni, Álvaro M. (2021): Reseña bibliográfica, “Thomas, R. (2019). Polis Histories, Collective Memories and the Greek World, Cambridge: Cambridge University Press, xii +490 pp." Anuario de la Escuela de Historia Virtual 19, 192-201. 